\title{
SOCIAL NETWORKS AND PROSPECTS FOR STUDENTS' PROFESSIONALIZATION
}

\section{Oksana V. Vasilenko ${ }^{1 *}$, Marina S.Sapriko², Tatiana A. Dzyuba ${ }^{3}$, Natalya I. Ivanova ${ }^{4}$, Avgusta V. Ulyandina ${ }^{5}$, Galina V. Ihonkina ${ }^{6}$}

\author{
${ }^{1}$ Assoc. Prof. Dr., Chuvash State University, RUSSIA, vasilenkoksana@rambler.ru \\ ${ }^{2}$ Assoc. Prof. Dr., Chuvash State University, RUSSIA, sapriko.m@mail.ru \\ ${ }^{3}$ Assoc. Prof. Dr., Chuvash State University, RUSSIA, dzyuba2004@mail.ru \\ ${ }^{4}$ Assoc. Prof. Dr., Chuvash State University, RUSSIA, orchestra@yandex.ru \\ ${ }^{5}$ Assoc. Prof. Dr., Chuvash State University, RUSSIA, avgusta.ulyandina@mail.ru \\ ${ }^{6}$ Senior lector, Chuvash State University, RUSSIA, gala-ihonkina@yandex.ru \\ ${ }^{*}$ Corresponding Author
}

\begin{abstract}
The article considers such factors as social networks and prospects for modern students' professionalization.

Based on the literature analysis on the problem of personal professionalization, data from the social networks analysis, the research hypothesis can be determined as follows: sociological survey of students for subscribing to personal accounts in social networks (for example, the social network "VKontakte") to professional communities and / or personal (personal) webpages of professionals in a certain field involves professionalization, professional development, involvement in the field of subsequent professional activities.

The objectives of the research are: firstly, based on the theoretical analysis of foreign and domestic literature, to identify the factors of the individual professionalization; secondly, to identify the possibilities of social networks (for example, the social network "Vkontakte") in professionalization; thirdly, to conduct a sociological survey of students for subscribing to social networks (for example, the social network "Vkontakte") to professional communities and/or personal webpages of professionals in a certain field; fourthly, to develop recommendations for teachers of educational institutions on using the social networks (for example, the social network "Vkontakte") in the modern students' professionalization; fifthly, to develop recommendations for increasing the interest of young people in social networks (for example, the social network "Vkontakte") as potential sources for posting information about your own professional skills, because nowadays, students do not consider virtual communication as a platform for self-presentation in professional terms and do not see the informational benefits of social networks (for example, the social network "Vkontakte") in terms of improving the effectiveness of their future employment.

Data from a sociological survey on the topic "Social networks and self-presentation (using the example of the social network "Vkontakte")", conducted in November 2019, were used as materials. At the same time, we analyzed data obtained only from 3rd - 4th year undergraduate students of the I.N. Ulianov Chuvash State University (Cheboksary, Russia). A total of 256 people (including 107 boys and 149 girls) were interviewed at the full-time departments of the Economics Faculty, the History and Geography Faculty, the Faculty of Computer Science and Engineering, the Faculty of Applied Mathematics, Physics and Information Technology.

The results of the research show that teachers and professionals in a certain field need to participate in professional communities in social networks. In modern realities, the educational system must learn to use the opportunities of mass communication with the maximum effect for itself.
\end{abstract}

Basing on the research, we can note that a small part of students are aware of the importance of professional self-presentation in social networks, and the following can be recommended for more effective 
inclusion of students.

Firstly, within the framework of career guidance, teachers need to conduct explanatory work aimed at acquainting students with the most popular specialties and areas of employment on the labor market at present time, as well as with the main requirements (not only professional, but also moral and ethical, image, etc.) imposed by employers on potential applicants.

Secondly, University teachers should warn students against rash imitation of modern opinion leaders, teach young people to carefully analyze the truth of the information broadcast by them and carefully check the accuracy of the information received from bloggers.

Thirdly, within the disciplines "Personal Career Management", "Management and Career Planning in the Socio-Cultural Sphere", you can apply the project method in the creative task "Building a personal brand in social networks", which will allow students to expand their skills in searching for professional information in the virtual space.

Thus, the students' professionalization as a process should include new opportunities in the form of using social networks to form the competencies of a future specialist.

Keywords: Professionalization, professional communities, student youth

\section{INTRODUCTION}

The process of the students' professionalization or the students' formation as future specialists, is not only of theoretical interest, but also has practical significance. According to the well-known Russian economist G.B. Kleiner, "the inefficiency of our economy lies in the fact that it lacks coordination mechanisms between its elements; it is fragmentary, mosaic, atomized" (Trushin, 2019). A similar situation is observed when considering the problem of training professional personnel. Every year universities graduate a large number of young specialists, but due to various circumstances, the labor market, nevertheless, is experiencing a shortage of them. On the one hand, this is due to conservatism, lack of flexibility in the education system, insufficient volume of career guidance work by teachers, on the other hand, the labor market is also poorly developed, there is not enough labor mobility.

In the modern education system, there is a trend of modernization for the labor market, which is associated with the innovative pedagogical technologies introduction into the learning process. At present, as it is known, the labor market highly values the social competence of a person - not only professional skills, but also the ability to work in a team, organize people, and independently solve workplace problems. The society is interested in well-trained and organized workers who are able to fulfill their potential (Trushin, 2019). Since any employer needs such an employee, universities consider professionalization as a long-term process, creating conditions for the adaptation of future specialists. It is for this reason that the problem of professionalization, agents and factors of professionalization is becoming more and more urgent.

Professionalization is understood as the process of becoming a specialist, including the choice of a profession by a person, taking into account his own capabilities and abilities; mastering the rules and norms of the profession; formation and awareness of oneself as a professional, gaining the profession experience through personal contribution, the development of one's personality by means of the profession, etc. (Professionalism).

Professionalization, in our opinion, is one of the types of socialization, such as politicization, culturalization, ecologization, etc.

The theoretical and practical study of a person professional development process is considered in the works of foreign and domestic scientists, for example, D.Super (Super, 1957), D.Holland (Holland, 1968), B.G. Ananyev (Ananyev, 1968), A.N. Leontiev (Leontiev, 2000) et al.

The article by O.A. Kozyreva (Kozyreva, 2008) is devoted to a review of foreign and domestic concepts of professional development.

V.A. Tsvyk (2003) reviews the literature on the professionalization problem, dividing this concept into several aspects: pedagogical, activity, sociological (stratification), socio-economic.

A.K. Markova (Markova, 1996) describes psychological criteria, levels, stages of advancement of a laboring person to professionalism, types of professional competence. 
A.A. Angelovsky (2011) considers the professionalization of an individual as a long-term process, conditioned by time and space, analyzing the purpose, meaning, mechanism of mastering the system of professional qualities, deep convictions, worldview positions that constitute the foundation for the professionalism development. In his article, a new paradigm of professional education is presented - the development of an active life and professional position in students, the ability to creative work, interest and the need for self-development.

A support in the analysis of the problem under study was the work by S.N. Makarova (Makarova, 2018), which considers scientific approaches in various areas (psychology, acmeology, sociology) to studying the concepts of "professionalization" and "professional socialization", identifies common and distinctive features that make it possible to designate the professionalization originality in a person's life and the complexity of determining the place of this process in socialization. The author expresses a point of view on the relationship between the concepts of "professionalization" and "professional socialization", interpreting "professionalization" as a form of professional socialization, as a certain and very important period of professional socialization, which lasts from the moment of choosing a profession until the end of labor activity.

Following I.A. Levitskaya (Levitskaya, 2014), S.N. Makarova (Makarova, 2018) considers the concepts "professionalization" and "professional socialization" to be identical.

It is well known that in the studying course at a university, primary professionalization takes place: universal and general professional competencies are formed among students, which are necessary for subsequent professional activities. The subsequent formation of a specialist depends on how successfully the primary professionalization is carried out. Not coincidentally that one of the criteria for the university effectiveness is the criterion of the demand for graduates in a specialty.

A practical understanding of the professionalization process is given in a study by L.E. Probst (Probst, 2013), in which the author notes that "the labor market for most young people remains unknown. This trend is not improving, it is only getting worse".

The complexity of primary professionalization lies in the fact that in its process any factor can work in both favorable and unfavorable ways.

Agents and factors of professionalization, such as family, educational institutions, public and state institutions, have been repeatedly considered in the previously mentioned works of domestic and foreign researchers.

Since the leading agent of primary professionalization is still a university, let us analyze the impact of such a factor as social networks. This problem has not been sufficiently studied for the present; moreover, its potential has not yet been fully used.

It is worth reminding that in recent decades there has been a rapid development in the field of information technology. With the formation and development of the Internet, this development, in addition to the area of purely technical interest, begins to affect the area of social phenomena, therefore, requires additional analysis, including from a socio-logical point of view. Currently, there are 3.3 billion Internet users in the world. They are individuals, businesspersons, and scientists, as well as enterprises and universities, government organizations and governments. Social networks have become widely in demand since 1995 with the emergence of the American portal Classmates.com, then similar services such as Linkedln, MySpace and Facebook (since 2003), Odnoklassniki and VKontakte (since 2006) are gaining popularity.

According to the Levada Center, every second Russian uses social networks to communicate with friends, every third - to interact with relatives, and every fourth looks for information and news in them. Staying in social networks is age-specific: young users under 30 more often use them to listen to music, search for information and entertainments. Young people are more likely to be interested in news about social life, technology and science, while adults in Russia are more interested in news about domestic politics, the economy and the environment (Social network).

The analysis of users' social media pages is a topical area of research. There are a number of scientific works devoted to the profiles analysis in the social network "VKontakte" in order to identify the value orientations of young people (Zabokritskaya, Khlebnikov, Oreshkina, Komotsky, 2020); to the young people motivation reflection in content blogs related to the topic of a healthy lifestyle, to create and maintain them (they also study the dependence of the blog popularity on the type of content (Kulpin, Savchuk, Yakimova, 2020); to the analysis of teenage communities, and also profiles on social networks in order to understand the picture of the sociocultural portrait of the modern adolescents generation (Kruglov, 2017). 
But, unfortunately, the works containing the analysis of the professional students' self-presentation in social networks are still clearly insufficient. Moreover, this, of course, is of great scientific interest, since it makes it possible to understand how professional interest is formed, the popularity of professionals in a certain field, their authority in the eyes of young people themselves. Analyzing the professional communities to which young people are subscribed, one can trace the development of these social phenomena and the degree of their pedagogical and psychological impact on the worldview of the younger generation. In other words, a user's profile on social networks is a kind of self-presentation, including professionally. The openness and accessibility of profiles on social networks make it possible to study the professional interests, inclinations and needs of modern students in a new way - using information technology. Observing the increase in subscriptions to professional communities and / or personal webpages of professionals in a certain field on social networks, we can receive information about the emerging demand for certain professions. Such sociological analysis makes it possible to predict in advance the prestige of a particular professional group, specialty and sphere of employment.

When talking about social networks, it is traditionally customary to highlight the communicative function, image component, news exchange and entertainment. Education and professionalization (selfprofessionalization) are new trends in social media. In this article, we will focus on a more detailed examination of the problem of the youth professional development through the prism of social networks, studying it from the point of pedagogical significance view.

It should be noted that professional communities in social networks are communities dedicated to professional self-expression. Conventionally, they can be divided into two subgroups: professional communities of social networks and professional communities in a certain (most popular) social networks of a general subject (VKontakte; Facebook; Odnoklassniki.ru; Moi Mir@mail.ru, etc.).

Professional communities of social networks are virtual associations in which you can share and enrich information on work or professional activity. Such networks can be differentiated depending on the hobbies of their users, for example, communities of photographers, musicians, hunters, motorists, etc. can be distinguished (Professionals.ru; E-xecutive.ru; Delovoy Mir, etc.).

For job seekers, professional social networks are necessary because they allow them to expand their circle of business acquaintances, exchange experiences and maintain relationships with former colleagues. Such communities are one of the tools for finding a job, media data is a source of useful information, and they can be used as a platform for business communication with the community. According to polls, between both groups of respondents, the most popular social network was Linkedln (blocked on the territory of the Russian Federation), the second place was taken by the E-xecutive managers club, and the third place was given by the applicants to the Professionali.ru business network, and the employers - to the professional network "Moi krug".

Any social networks (VKontakte; Facebook; Odnoklassniki.ru; Moi Mir@mail.ru, etc.) also perform the function of professional self-realization. The most popular in Russia are (according to the Deloitte study) the sites VKontakte, YouTube and Odnoklassniki, then Instagram and Facebook (Audience of social networks in Russia 2019). Moreover, VKontakte (initially the social network was conceived as a student, the working name is Studlist.ru) and Instagram are most popular with audiences aged 16-24, and Facebook - with an audience over 45. Among the older age group (55 and older), YouTube, Odnoklassniki and VKontakte are popular.

The study analysis of social networks shows that there is an overlap of the social networks audience. Few of the users remain committed to one online platform.

Social media studies show that different audiences can be distinguished by gender, age, education, etc. Researcher D.V. Vinnik (Vinnik, 2012) notes that "the analysis of social networks allows us to interpret social interactions in terms of network theory (an interdisciplinary line of research that is part of graph theory and the science of networks), within which individual agents and connections between them are studied". Analysis of other sources allows us to classify social networks into categories such as: 1 ) type (personal communication, business communication, video, audio, photo, geolocation, shopping, blogging, news, question-answer, bookmarks, virtual worlds, thematic, entertainment / acquaintances); 2) openness of information (open, closed, mixed); 3) geographical coverage (world, country, territorial unit, without region international); 4) level of development (web 1.0 - web 3.0) (Voronkin, 2014).

In earlier studies, most often under social networks, traditional channels of employment are considered as personal connections in the search for work. For example, in the article by P.E. Lavrusevich (Lavrusevich, 2006) it is noted that the most widespread channel of job search in the Russian labor market for the present is social networks. According to the author, "the action of social networks as an intermediary in the labor 
market can be divided into reactive (i.e. assistance in employment, initiated by the request of the individual himself) and proactive (i.e., initially not planned and not initiated by the individual himself) - the desire of any agent of a social network to assist in employment)". The conclusions made in this study boil down to the fact that the presence of social networks is more or less characteristic of all labor markets (primarily as an information intermediary). It is only important to determine where the border of excess presence lies, what are the criteria for the hypertrophied role of social networks, and nowadays this question remains open.

I.A. Bobkova (Bobkova, 2009) suggests using as one of the criteria the network communities' creation in accordance with the selected audience, taking the professional attribute as a basis. A.A. Lisenkova and A.Yu. Melnikova (Lisenkova, Melnikova, 2017) consider the phenomenon of "virtual" social media as a factor influencing the markers formation of the value palette and preferences of modern youth. The authors in their study came to the conclusion that the dominant force of social networks is the self-affirmation of a person with an active representative model, included in various communities, living and acting according to the rules of these groups and receiving social approval and support, which often leads to a break with cultural tradition and the formation of a new personality type, which determines the novelty and relevance of the research in the modern conditions of the digital society development.

One of the tasks of professional communities in social networks is the development of professional connections, in which communication is a rationally conditioned action, the opportunity to get a business recommendation, exchange experience with specialists, get answers to specialized questions, the use of popular business networks is an additional opportunity once again declare yourself as a professional among colleagues.

At present time, most employers have at least one registered account in such networks - there they can get additional information about current and future employees, find new business connections, place advertisements for new vacancies among the target audience.

Jobseekers are also increasingly looking for work through the aforementioned sites: according to statistics, they provide jobs for about a third of users.

The reference list should be given at the end of the paper in alphabetical order according to the last name of the first author.

\section{RESEARCH METHODS}

Today social networks are a kind of technology for spreading knowledge, including professional ones. Student youth are involved in social networks; therefore, as mentioned earlier, the most relevant analysis is the profile in social networks for professional communities and / or personal webpages of professionals in a certain field. The use of sociological methods can help to identify the factors influencing the professional socialization of student youth.

To confirm this thesis, we carried out the following research. As materials, we used the data of a sociological survey on the topic "Social networks and self-presentation", conducted in November 2019. The objects of the research were students receiving education in three areas of training: humanitarian, natural science and technical. At the same time, we analyzed the data obtained only from students of the $3^{\text {rd }}-4^{\text {th }}$ courses of the Bachelor's programme at the I.N. Ulianov Chuvash State University (Cheboksary). This limitation was caused by the following considerations: the university was chosen, where three areas of training are presented: humanitarian, natural-scientific and technical (a survey of students studying in the specialties "State and Municipal Management"; "Economics"; "Land Management and Cadaster", "Geography", "Ecology and Nature Management", "Applied Informatics and Mathematics", "Applied Informatics in State and Municipal Administration"). Also, the survey limitation of the $3^{\text {rd }}-4^{\text {th }}$ year students was due to the subject of the research: it was taken for the assumption that junior students, as a rule, have less ideas about their future professional activities, since they have introduction practical training in the $1^{\text {st }}$ year, and curricular practical training - in the $2^{\text {nd }}$ year, and only on the $3^{\text {rd }}$ and $4^{\text {th }}$ courses according to educational standards they have production practical training. Accordingly, the research is of a representative nature for the universities of Cheboksary. 256 people were interviewed (including 107 boys and 149 girls) of the full-time department of the Economics Faculty, the History and Geography Faculty, the Faculty of Computer Science and Computing, the Faculty of Applied Mathematics, Physics and Information Technology. Such a volume made it possible to obtain conclusions about the reliability or unreliability of the hypotheses of this research, in addition, the work carried out was of a pilot nature.

The general structure of the questionnaire consisted of two parts. The first part of the survey was devoted to the collection of material characterizing the personality of the interviewed student according to a number of common socio-demographic characteristics: age, gender, course of study, social status, etc. The second part 
was devoted to the collection of data characterizing the student's presence in social networks.

\section{RESULTS}

Among the interviewed, the distribution of respondents by gender was expressed in the following way: $41.8 \%$ - boys and $58.2 \%$ - girls. Age distribution: $18-19$ years old - 10.9\%; 20-21 years old - 82.8\%; 22 years and older $-6.3 \%$ of respondents. $45.3 \%-3^{\text {rd }}$ year students, $54.7 \%-4^{\text {th }}$ year respondents.

The results of the survey showed that all respondents were registered in social networks, and even in several.

Since this research was of a pilot nature, it is worth noting the relevance and reliability of the information obtained during the survey at the current moment.

As part of the survey, the respondents were asked about the importance of their own account in the professional sense.

Table 1

Distribution of answers to the question:

Is it important for your profession to have your own online account?

\begin{tabular}{|l|l|l|l|l|}
\hline Answer variants & $\begin{array}{l}\text { Total } \\
(\%)\end{array}$ & $\begin{array}{l}\text { Humanitarian } \\
\text { training (\%) }\end{array}$ & $\begin{array}{l}\text { Natural science } \\
\text { training (\%) }\end{array}$ & $\begin{array}{l}\text { Technical training } \\
(\%)\end{array}$ \\
\hline 1. Yes & 19.1 & 18 & 12.3 & 26.3 \\
\hline 2. Rather yes & 25.4 & 26.1 & 10.8 & 36.3 \\
\hline 3. Rather no & 19.5 & 16.2 & 27.7 & 17.5 \\
\hline 4. No & 17.2 & 21.6 & 21.5 & 7.5 \\
\hline 5. Neither agree nor disagree & 19.1 & 18.9 & 27.7 & 12.5 \\
\hline
\end{tabular}

Data analysis by training program shows that students of the technical faculties have a more complete understanding of the role of social networks as an indicator of their professional interests.

The data obtained indicate that most of the respondents do not yet realize the importance of their own account on social networks (17.2\%).

Table 2

Distribution of answers to the question:

Do you consider representing yourself as a specialist in the information field, in the INTERNET (Do you have your own account, subscribed to professional communities, etc.)?

\begin{tabular}{|l|c|c|c|c|}
\hline Answer variants & $\begin{array}{c}\text { Total } \\
(\%)\end{array}$ & $\begin{array}{c}\text { Humanitarian } \\
\text { training (\%) }\end{array}$ & $\begin{array}{c}\text { Natural science } \\
\text { training (\%) }\end{array}$ & $\begin{array}{c}\text { Technical training } \\
(\%)\end{array}$ \\
\hline 1. Yes & 14.8 & 9 & 18.5 & 20 \\
\hline 2. Rather yes & 37.1 & 31.5 & 33.8 & 47.5 \\
\hline 3. Rather no & 38.3 & 36 & 64.6 & 20 \\
\hline 4. No & 16 & 20.7 & 20 & 6.3 \\
\hline 5. Another & 3.1 & 1.8 & 3.1 & 5 \\
\hline
\end{tabular}

In turn, students of the technical faculties are more interested in promoting themselves as specialists through 
their accounts in social networks (47.5\% of respondents indicated a readiness for such a demonstration of their educational and professional achievements).

In the modern world, for certain professions, for example, for creative specialties or political and public figures, it is imperative to be present and actively maintain their webpages on social networks to maintain feedback with the target audience. This kind of survey makes a young person think about what kind of idea about him arises when he gets acquainted with his page: the level of general culture, the specifics of his worldview (political views, belonging to a particular subculture, religion, sexual orientation), interests and hobbies, ethical behavior. It should be borne in mind that companies that care about their own positive image and reputation can unilaterally terminate an agreement with an employee whose virtual behavior can harm the organization.

The survey results show that most of the students have not yet come to the realization that an account on social networks can have the status of a professional, so such answers are not surprising, as they do not consider themselves as specialists in the information field. Only $14.8 \%$ of respondents are subscribed to professional communities and / or personal webpages of professionals in a certain field, but the analysis of answers to the open question "Who is an example of professional self-realization for you in information networks?" showed that these respondents are mainly students of the technical training, subscribed to the developers of computer games and bloggers - programmers, which in terms of topics is closer to their professional choice.

To the open question "Who is an example of professional self-realization for you in information networks?" 65 answers (25.3\%) were given, of which $36.9 \%$ of respondents named bloggers (for example, Anastasia Ivleeva, Oksana Samoilova, Dmitry Belostotsky, Igor Voitenko, Anastasia Mironova, Alexandra Mitroshin, etc.), $16.9 \%$ of respondents cited the names of programmers and developers of computer games (Mark Zuckerberg, Steve Jobs, Bill Gates, Elon Musk, etc.), 9.2\% of students cited the names of politicians, including those of the regional level (most often students named Alena Arshinova, the secretary of the Chuvash regional branch of United Russia, who actively maintains her webpage on social networks). If we talk about the phenomenon of blogging, then a third of the respondents (36.9\%) named as an example personalities engaged in this type of activity, which, according to students, have large earnings without the need for serious investments, education, specialization, etc., which, no doubt, is attractive to most young people. Many students surveyed believe that blogging can become a profession, while they do not take into account the fact that it has not yet been enough time to conclude about the significance and longevity of this phenomenon.

In fact, we are dealing with such a phenomenon as self-presentation in the virtual space. The analysis of profiles in social networks indicates the set of communities in which the respondent is, thus, conclusions can be drawn about his (respondent's) interests, including professional ones. The number of network members subscribed to the community and / or personal webpages of professionals in a certain field reflects the picture of the popularity of a particular resource, organization, idea; however, you should also take into account the possibility of unscrupulous, fraudulent schemes to attract subscribers to a particular community.

Having a well-designed social media account can be one of the employment channels. So, in 2019, a survey was conducted on the website hh.ru (Not invited to work? The problem may be in your social media profile, 2019). According to the results of this survey, it turned out that $84 \%$ of employers already check the pages of job seekers in social networks, in $22 \%$ of cases - always (for any position). $72 \%$ of employers admitted that they changed their minds about inviting a candidate to work after viewing his personal profile in social networks.

It should be noted that our analysis of the data allows us to conclude that the creation of webpages on social networks by students is more abstract, since young people are most often subscribed to the accounts of people (opinion leaders) who do not necessarily have professional competencies, i.e. those who just managed to monetize their fame.

Judging by the research results, students do not consider virtual communication as a platform for selfpresentation in a professional sense, therefore, modern young people often do not see the informational benefits of social networks in terms of increasing the efficiency of future employment. In other words, students do not audit their social media webpage.

Accordingly, the study of students' profiles on social networks for their membership in professional communities and / or subscription to personal webpages of professionals in a certain field allows us to receive information about professional interests and plans for further professional self-realization, as well as about authorities in a particular professional field. 


\section{CONCLUSION}

The results of the given research show that teachers and professionals in a certain field (practitioners) need to participate in professional communities. In modern realities, the educational system must learn to use the possibilities of mass communication with the maximum effect for itself. Social networks can be used in project activities for the professionalization of future specialists. Students need to be trained to correctly select communities and professionals in a certain field, information from which will be useful, since there are negative examples of bloggers who do not have fundamental knowledge, but consult for money; communities whose activities go beyond the legal field; there is also an excess of irrelevant and unreliable information.

On the basis of the conducted research, it can be noted that a small part of students are aware of the importance of self-presentation in social networks, for a more effective inclusion of students, the following can be recommended.

Firstly, within the framework of career guidance, teachers should conduct explanatory work aimed at acquainting students with the specialties and areas of employment that are most in demand on the labor market at the moment, as well as with the basic requirements (not only professional, but also moral, ethical, image and etc.), presented by employers to potential job seekers. It is important to demonstrate examples of correctly designed accounts in social networks belonging to specialists already employed and successfully realizing their working potential, as well as to reveal the basic rules and principles of adequate user behavior on the Internet, effective promotion and memorable self-presentation of their own professional skills, knowledge and services.

Secondly, university teachers should warn students against ill-considered imitation of modern opinion leaders, teach young people to carefully analyze the truth of the information broadcast by them and subject them to a thorough check of the information reliability received from bloggers. It is necessary to draw the students' attention to the doubtfulness and instability of the demand for this or that blogger or another person, whose example they are trying to follow in terms of the way of earning money or the nature of future work.

Thirdly, within the framework of the disciplines "Personal Career Management", "Management and Career Planning in the Sociocultural Sphere" and "Management and Project Activities in the Sphere of Culture, Education and Science", you can apply the project method in the creative task "Building a personal brand in social networks", which will allow students to expand their skills in searching for professional information in the virtual space. The purpose of this assignment will be to study the profiles of professional communities, professionals who have an account in social networks, dividing them into such components as image (personal self-presentation), positioning, strategic plan, communication. It is also necessary to analyze the number of contacts and the quality of the content - what kind of posts a person makes and whether he writes correctly, whether he supports professional topics, whether he attends professional events.

The project implementation will allow the student to look at his future profession from a creative position and from the point of view of practical results. The use of the project method will enable teachers to realize the main didactic task - instilling in students the skills of critical thinking and the ability to select information in terms of its relevance, reliability and relevance to the topic.

Summing up, we can state that in the educational process it is necessary to use actively information resources, including social networks, since this opens up unlimited opportunities for broadcasting scientific information, and allows students to declare themselves as young professionals on a very extensive audience, which includes potential employers.

Thus, the students' professionalization as a process should include new opportunities of using social networks to form the competencies of a future specialist.

\section{REFERENCE LIST}

Ananiev, B.G. (1968). Man as a subject of knowledge.

Angelovsky, A.A. (2011). Personality professionalization. Social agents of primary and secondary professionalization. Siberian Pedagogical Journal, 7.

Audience of social networks in Russia (2019) URL: https://popsters.ru/blog/post/auditoriya-socsetey-v-rossii. 
Bobkova, I.A. (2020). Development of a classification for the analysis of social networks. URL: http://www.mce.biophys.msu.ru/archive/doc57318/doc.pdf.

Vinnik, D.V. (2012) Social networks as a phenomenon of the organization of society: the essence and approaches to the use and monitoring. Philosophy of Science, 4 (55).

Voronkin, A.S. (2014). Social networks: evolution, structure, analysis. Educational technologies and society, 1. URL: http://ifets.ieee.org/russian/depository/v17 i1/pdf/21.pdf.

Zabokritskaya, L.D., Khlebnikov, N.A., Oreshkina, T.A., Komotsky, E.I. (2020). Opportunities for studying the values of youth through the profile of the social network "Vkontakte". Monitoring of public opinion: economic and social changes, 2. URL: https://doi.org/10.14515/monitoring.2020.2.692.

Kozyreva, O.A. Concepts of professional development (2008). Primary school before and after. 5. URL: http://school2100.com/upload/iblock/176/17606c5d53543e11fae4b5f75df4565d.pdf.

Kruglov, V.V. (2017). Information technologies in the field of obtaining scientific knowledge in the field of education. Bulletin of PSTGU. Series IV: Pedagogy. Psychology. 47.

Kulpin, S.V., Savchuk, G.A., Yakimova, O.A. (2020). Why does young people create content about a healthy lifestyle: factor analysis of thematic blogs. Monitoring of public opinion: economic and social changes, 2. URL: https://doi.org/10.14515/monitoring.2020.2.656.

Lavrusevich, P.E. (2006). Social networks in employment strategies on the Russian labor market. Economic sociology, 7(2).

Levitskaya, I.A. (2014). The concept of professionalization: social and personal factors. Modern science: actual problems of theory and practice. Series: Humanities, 1-2.

Leontiev, A.N. (2000). Lectures on general psychology.

Lisenkova, A.A., Melnikova, A.Yu. (2017). Social networks as a factor of active influence on the formation of youth values. Russian humanitarian journal, 6(4).

Makarova, S.N. (2018). Basic approaches to the study of the relationship between the concepts of "professional socialization" and "professionalization". Modern problems of science and education, 5.

Markova, A.K. (1996). Psychology of professionalism.

Not invited to work? Perhaps the problem is with your social media profile (2020) URL: https://hh.ru/article/24311.

Probst, L.E. (2013). Professional socialization and deprofessionalization of Russian youth in the context of educational reform. Culture, personality, society in modern conditions: methodology, experience of empirical research in memory of Professor L. N. Kogan.

Professionalization. (2020). Dictionary of career guidance and psychological support. URL: http://technomag.edu.ru/doc/42344.html.

Social networks. (2019) URL: https://www.levada.ru/2018/03/06/sotsialnye-seti/

Trushin, A. (2019). Abroad will not help. The list of scarce professions in the Russian Federation has doubled in four years. Ogonek, 45.

Tsvyk, V.A.(2003). Professionalization as a social process. Bulletin of RUDN University, series Sociology, 45.

Holland, Y.L. (1968). Explorations of a theory of vocational choice. J. Appl. Psychol.

Super, D.E. et al. (1957). Vocational Development: A Framework of Research. 